\title{
Atividade pozolânica dos resíduos cauliníticos das indústrias de mineração de caulim da Amazônia
}

\author{
BARATA, M.S., ANGÉLICA, R.S.
}

Laboratório de Caracterização Mineral - LCM - Instituto de Geociências/ UFPA, Av. Augusto Correa, 1, Guamá, CEP: 66075-110, Belém Pará.

e-mail: marciosbarata@yahoo.com.br ; angelica@ufpa.br

\section{RESUMO}

As regiões do Rio Capim e do Rio Jari são os principais distritos caulinitícos da Região Amazônica, detentores das maiores reservas brasileiras de caulim de alta alvura para aplicações como cobertura de papel. No processamento do caulim são gerados vários tipos de resíduos processados e não processados.

O objetivo deste trabalho foi investigar a reatividade das pozolanas produzidas a partir da calcinação e moagem destes resíduos, avaliando a influência da mineralogia de cada tipo de caulinita (com maior ou menor quantidade de defeitos na estrutura cristalina) sobre a temperatura de queima e, consequentemente, nas características do produto final, de modo a obter o material de maior reatividade com um menor dispêndio de energia.

Os resultados mostraram que as pozolanas produzidas a partir dos resíduos apresentaram alta reatividade, sendo inclusive superiores as das obtidas com as pozolanas disponíveis comercialmente. As pozolanas produzidas das caulinitas com maior grau de defeitos na estrutura cristalina demandaram temperaturas mais reduzidas que a com menor grau de defeitos. O emprego de caulinitas com maior quantidade de defeitos na estrutura cristalina reduz os custos de produção das pozolanas, sem que haja perda de qualidade ou de reatividade do produto.

Palavras chaves: resíduos, pozolana, metacaulim, calcinação, alta reatividade.

\section{Pozzolanic activity of kaolin wastes from kaolin mining industry from the amazon region}

\section{ABSTRACT}

The Capim and Jari regions, northern Brazil, are the main Kaolin mining areas in the Amazon region. They encompass the biggest high-grade (high whiteness) kaolin reserves for the paper coating industry. During the beneficiation of this kaolin, different kinds of processed and non-processed wastes are generated.

The main objective of this work was to evaluate the reactivity of pozolans produced after calcinations and milling of such residues, by the comparison of the mineralogical composition and the type of kaolinite from the two regions (different kinds of structural order/disorder). The heating temperature to produce the pozolans was evaluated in order to obtain the better reactivity with lower energy consumption.

The results showed that the pozolans obtained from both residues exhibited high reactivity, also better than those commercially available. Those obtained from kaolinites with high structural defects needed lower temperatures in comparison with low-defects kaolinites. The use of the former kaolinites reduces the production costs to obtain pozolans without losing quality in terms of reactivity

Keywords: kaolin wastes, pozzolan, metakaolin, calcination, high reactivity

\section{INTRODUÇÃO}

O caulim é um minério amplamente utilizado por diversos setores industriais, principalmente pelo de papel, que consome cerca de $45 \%$ da produção mundial, dos quais $32 \%$ para revestimento ou cobertura (“coating”) e 13\% para carga (“fíller”). As reservas brasileiras estão localizadas, quase na sua totalidade, na região norte do país, mais especificamente nos Estados do Pará, Amapá e Amazonas. Caracterizam-se por serem constituídas de depósitos secundários que ocorrem a partir da erosão dos depósitos primários e sedimentação em grandes bacias. Os caulins deste tipo de depósito possuem teores de caulinita geralmente 
acima de $90 \%$ e são mais conhecidos como caulim "coating”, apropriados para aplicações do tipo cobertura de papel por causa da sua elevada alvura, granulometria e viscosidade. Esses tipos de depósitos até então eram conhecidos somente nos EUA (Geórgia e Carolina do Sul) e na Inglaterra (Cornwall) [1]].

No Estado do Pará estão localizadas as principais empresas de beneficiamento de caulim do Brasil: a Imerys Rio Capim Caulim (IRCC), a Pará Pigmentos SA (PPSA) e a CADAM SA. A CADAM SA possui parte das instalações localizadas no Estado do Amapá, uma vez que explora a jazida do Morro do Felipe (Rio Jarí), localizada no Município de Laranjal do Jarí. A IRCC e a PPSA exploram o caulim do Distrito Caulinítico do Rio Capim, na região localizada a NE do Estado do Pará, entre a rodovia Belém-Brasília (trecho entre Ipixuna do Pará e Mãe do Rio) e o médio curso do Rio Capim [2, $\underline{3}$ ].

No processo de beneficiamento do caulim são gerados dois principais tipos de resíduos processados, sendo que o mais importante é o procedente das etapas a partir da centrifugação, denominado neste trabalho de resíduo da centrifugação (RC). Estudo preliminar de caracterização [4] mostrou que esses resíduos, tanto da exploração das jazidas do Morro do Felipe (RCJ) quanto do distrito caulinítico do Rio Capim (RCC), possuem características apropriadas para serem empregados como matérias primas para a produção de uma pozolana denominada metacaulim de alta reatividade (MCAR), uma vez que são constituídos essencialmente por caulinitas de baixa granulometria.

BARATA e ANGELICA [4] destacam que além da finura e da pureza, a quantidade de defeitos na estrutura cristalina pode ser o parâmetro mais importante para escolha da caulinita como matéria-prima para a produção do metacaulim. Isto porque caulinitas com maior quantidade de defeitos na estrutura cristalina, ou mal cristalizadas, quando calcinadas apresentam maiores taxas de desidroxilação em relação as caulinitas com menor grau de defeitos (bem cristalizadas), o que permite produzir uma pozolana com alta reatividade a temperaturas menores, o que se traduz em menor custo energético. No caso em questão, a caulinita do RCJ pode ser a mais adequada que a do RCC do ponto de vista econômico para a produção da pozolana, uma vez que é uma caulinita com maior grau de defeitos na estrutura cristalina.

No RCC, a caulinita é bem cristalizada, pois apresenta picos agudos e de alta intensidade nos ângulos $2 \theta$ de $12,46^{\circ}$ e $25,05^{\circ}$ e tripletes com reflexões bem individualizadas localizados entre $35^{\circ}$ e $40^{\circ} 2 \theta$ $(2,55$ a $2,24 \AA)$. No caso do RCJ, a caulinita possui uma quantidade de defeitos superior a da RCC uma vez que o primeiro triplete situado entre $19,9^{\circ}$ e $23,8^{\circ} 2 \theta$ (4,70 a 3,73 $\AA$ ) encontra-se sob a forma de uma banda associada a um único pico bem individualizado. Já os outros dois tripletes, localizados entre $35^{\circ}$ e $40^{\circ} 2 \theta$

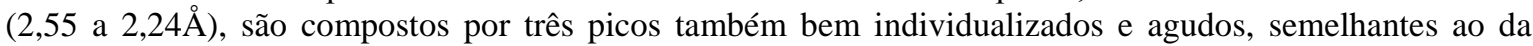
caulinita do RCC. Embora a caulinita do RCJ seja considerada com alto grau de defeitos por conta do primeiro triplete, pois apresenta desordem ao longo do eixo b, as reflexões são bem desenvolvidas, o que denota um grau de desordem limitado [4].

No trabalho de BARATA e ANGÉLICA [4], a quantificação do grau de cristalinidade das caulinitas foi determinada pelo método de Hinckley, conhecido como índice de cristalinidade de Hinckley. O IH determinado para a amostra com menor quantidade de defeitos, no caso o RCC, foi de 1,30. Para a amostra do RCJ, em razão da maior quantidade de defeitos, o IH foi de 0,3 .

Além dos resíduos processados, oriundos do beneficiamento do caulim, há um outro resíduo proveniente do processamento dos caulins da Amazônia, neste caso não processado. É o caulim tipo "flint" (CF), material estéril que não é aproveitado no beneficiamento por não dispersar suas partículas na água e possuir uma coloração bege. É encontrado somente na jazida do Rio Capim, sobreposto ao caulim "soft" (extrato de caulim que é submetido ao processo de beneficiamento). BARATA [ㅁ] constatou que o CF, assim como o resíduo processado da jazida do Rio Jari (RCJ), também é constituído basicamente por uma caulinita extremamente fina e com alto grau de desordem na estrutura cristalina.

O MCAR é empregado normalmente como substituição parcial do cimento Portland na produção de argamassas e concretos de alto desempenho - materiais utilizados na construção de edificações e estruturas cujos requisitos essenciais de projeto são a durabilidade e resistência mecânica elevadas. Os mecanismos de ação desta pozolana nos sistemas à base de cimento Portland são semelhantes aos da sílica ativa (SA), com a vantagem de ser um material de extrema alvura, que o habilita para inúmeras aplicações decorativas em que 0 aspecto estético é fundamental $[\underline{6}, \underline{7}, \underline{8}]$. O MCAR é proveniente da queima de caulins com alto teor de pureza ((> 90\% de caulinita), que são relativamente raros [9]. Por esta razão, geralmente a matéria-prima (caulim) necessita de algum tipo de beneficiamento que remova os minerais inertes e conseqüentemente aumente a concentração do mineral pozolanicamente ativo, a caulinita. O fato dos RC e CF possuírem alta pureza e uniformidade dessa característica é extremamente favorável ao seu co-processamento, pois dispensaria as etapas de remoção de impurezas. Este aspecto reduziria os custos de fabricação do MCAR a partir desses resíduos cauliníticos [4].

O objetivo deste trabalho foi investigar a reatividade das pozolanas produzidas a partir da calcinação e moagem dos resíduos caulinitícos oriundos das indústrias que exploram os depósitos secundários de caulim da Amazônia, avaliando a influência da mineralogia de cada tipo de caulinita (com maior ou menor quantidade de defeitos na estrutura cristalina) sobre a temperatura de queima e, conseqüentemente, nas 
características do produto final, de modo a obter o material de maior reatividade com um menor dispêndio de energia.

\section{MATERIAIS E MÉTODOS}

Neste trabalho foram estudados três tipos de resíduos cauliníticos, dois processados e um não processado. Com relação aos processados, o primeiro é procedente de uma indústria que beneficia o caulim do Rio Jari (RCJ) e o outro do distrito caulinítico do Rio Capim (RCC). O resíduo não processado, o caulim "flint” (CF) também é proveniente da região do Rio Capim, região Nordeste do Pará. O programa experimental consistiu na produção das pozolanas nas temperaturas de calcinação de $750^{\circ} \mathrm{C}, 850^{\circ} \mathrm{C}$ e $900^{\circ} \mathrm{C}$ e avaliação das suas atividades pozolânicas.

As pozolanas produzidas foram provenientes da calcinação e moagem dos RCJ, RCC e CF. Todas as amostras "in natura" dos caulins encontravam-se pulverizadas, com 100\% passante na peneira \# 200 $(0,075 \mathrm{~mm})$. A produção das pozolanas teve como procedimento inicial a secagem das amostras até a constância de massa em estufa a $105^{\circ} \mathrm{C}$. Em seguida, $700 \mathrm{~g}$ de amostra seca de caulim eram pesadas em cadinhos de aço inox revestidos internamente com cimento refratário. Os cadinhos eram colocados na mufla quando a temperatura da mesma alcançasse a temperatura desejada, no caso $750^{\circ} \mathrm{C}, 850^{\circ} \mathrm{C}$ ou $900^{\circ} \mathrm{C}$. $\mathrm{O}$ tempo de permanência de cada amostra na mufla era de 70 minutos. Decorrido esse período de permanência na mufla, as amostras eram retiradas para serem resfriadas naturalmente ao ar. Como houve aglomeração das partículas, todas as amostras foram então cominuídas em moinhos planetários por 10 minutos, de modo que apresentassem 100\% de material passante na peneira \#200 mesh. A quantidade de amostra introduzida na mufla e o seu tempo de permanência foram estipulados através de estudo preliminar que objetivou compatibilizar a massa de material com a potência e a capacidade do equipamento. Neste estudo preliminar, o parâmetro de referência adotado foi o mesmo empregado pelas indústrias de produção de cimento locais, que emprega como indicador de controle na produção de metacaulim a correlação entre perda de massa residual e temperatura de queima. Em números, o valor de 1 a $4 \%$ de perda de massa residual é associado à temperatura de queima entre 700 e $800^{\circ} \mathrm{C}$.

Os materiais estudados nessa pesquisa totalizaram 11 (onze) pozolanas, sendo 09 (nove) metacaulins produzidos a partir dos três tipos de resíduos, calcinados em três temperaturas distintas, e duas pozolanas industriais: a SA e um MCAR produzido industrialmente (MI). A SA utilizada na pesquisa foi um subproduto de uma indústria de produção de silício-metálico, disponibilizada comercialmente pela TECNOSIL. O MI estudado também foi proveniente da METACAULIM DO BRASIL, indústria que comercializa este produto para produção de concreto de alto desempenho.

A composição mineralógica foi determinada por difração de raios - X (DRX). As características físicas avaliadas foram a massa específica, a distribuição granulométrica das partículas e a área superficial específica (BET). As determinações da curva granulométrica e do diâmetro médio das partículas (DMP) foram realizadas através de granulômetro baseado no princípio de difração a laser, da marca CILAS, modelo 715 E 701, após a moagem do material calcinado.

As amostras foram submetidas às análises por DRX pelo método do pó (amostra total). O equipamento utilizado para as análises de DRX foi um difratômetro da marca Philips, modelo PW 1050, equipado com goniômetro de varredura vertical e tubo de cobre de $1,5 \mathrm{~kW}$ de potência $(\lambda \mathrm{CuK} \alpha 1=1,54060 \AA)$, com monocromador, além de gerador de tensão e corrente ajustados para $45 \mathrm{kV}$ e $35 \mathrm{~mA}$, respectivamente. Este equipamento é automatizado, com registro digital dos resultados, sendo o gerenciamento do equipamento realizado por intermédio do software APD (“Automated Powder Diffraction”), também da Philips. Os registros foram realizados no intervalo de exposição de $5^{\circ}$ a $65^{\circ} 2 \theta$. O tratamento dos dados foi realizado com o software High Score, da Panalytical.

As técnicas empregadas para determinação da atividade pozolânica foram as seguintes: o ensaio químico denominado "Chapelle" e o mecânico tradicional em argamassas de cimento Portland. Os resultados desses testes acelerados permitiram a determinação da temperatura ótima de calcinação para cada tipo de resíduo.

O ensaio "Chapelle" modificado mede a quantidade de $\mathrm{CaO}$ que reage com a pozolana avaliada. O procedimento consiste em manter em ebulição, durante 16 horas, uma mistura de $1 \mathrm{~g}$ de óxido de cálcio, $1 \mathrm{~g}$ de pozolana e água. O resultado é determinado por titulometria e é expresso pela quantidade de óxido de cálcio consumido ou fixado por grama de material pozolânico (mg CaO/g pozolana), sendo que a precisão é de $\pm 5 \%$. O ensaio foi executado no Instituto de Pesquisas Tecnológicas de São Paulo (IPT). Para cada pozolana foram realizadas 02 determinações.

Para o ensaio mecânico em argamassas com cimento Portland seguiram-se as diretrizes da NBR 5752 [10], na qual a determinação da atividade pozolânica de um material é função do comportamento mecânico de duas argamassas, preparadas com traço em massa de 1:3 e consistência padronizada de $225 \pm 5 \mathrm{~mm}$ (mesa de consistência). A primeira argamassa, admitida como de referência, utiliza apenas 
cimento, areia normal e água, enquanto que na segunda argamassa, parte do volume de cimento (35\%) é substituído pela pozolana que se pretende analisar. O índice de atividade pozolânico com cimento Portland (IAP) é definido como a relação entre as resistências à compressão aos 28 dias da argamassa com pozolana e cimento Portland e a de referencia (somente com cimento Portland). Os valores de resistência à compressão de cada argamassa foram obtidos através da média de 03 (três) corpos de prova. Para que um material seja considerado pozolânico, este índice, normalmente expresso em porcentagem, deve ser superior a 75\%. Foram moldadas 12 argamassas, sendo uma de referência e as outras onze relacionadas aos três tipos de caulins calcinados em três diferentes temperaturas, a SA e ao MI. O cimento utilizado foi o cimento Portland de alta resistência inicial (ARI), de acordo com a NBR 5733 [11], cuja composição varia de 95 a 100\% de clíquer mais gipsita e de $0 \%$ a $5 \%$ de material carbonático (fíler). A escolha recaiu neste tipo de cimento porque é isento de incorporação de pozolanas.

\section{RESULTADOS E DISCUSSÃO}

\subsection{Caracterização das Pozolanas}

Os difratogramas de raios $\mathrm{X}$ dos três resíduos calcinados às temperaturas de $750^{\circ} \mathrm{C}, 850^{\circ} \mathrm{C}$ e $900^{\circ} \mathrm{C}$ são mostrados nas Figuras 1 a 3 e as suas características físicas encontram-se na Tabela 1. De modo geral, independente do tipo de caulim, as amostras calcinadas apresentaram duas expressivas bandas de amorfização entre os ângulos $2 \theta$ de $10^{\circ}$ e $30^{\circ}$, intervalo esse normalmente caracterizado por reflexões fortes e agudas da caulinita, o que evidencia a presença da metacaulinita nos resíduos calcinados. Quanto maior a temperatura de calcinação, maior foi o grau de desidroxilação (desordenamento) da caulinita, conforme mostrado pelos valores de perda ao fogo (Tabela 1). Com o desaparecimento dos picos da caulinita em prol do surgimento da metacaulinita, detectou-se o anatásio e quartzo nos resíduos CF e RCC.

Tabela 1: Características físicas dos caulins “in natura” e calcinados a 750, 850 e $900^{\circ} \mathrm{C}$ e moídos.

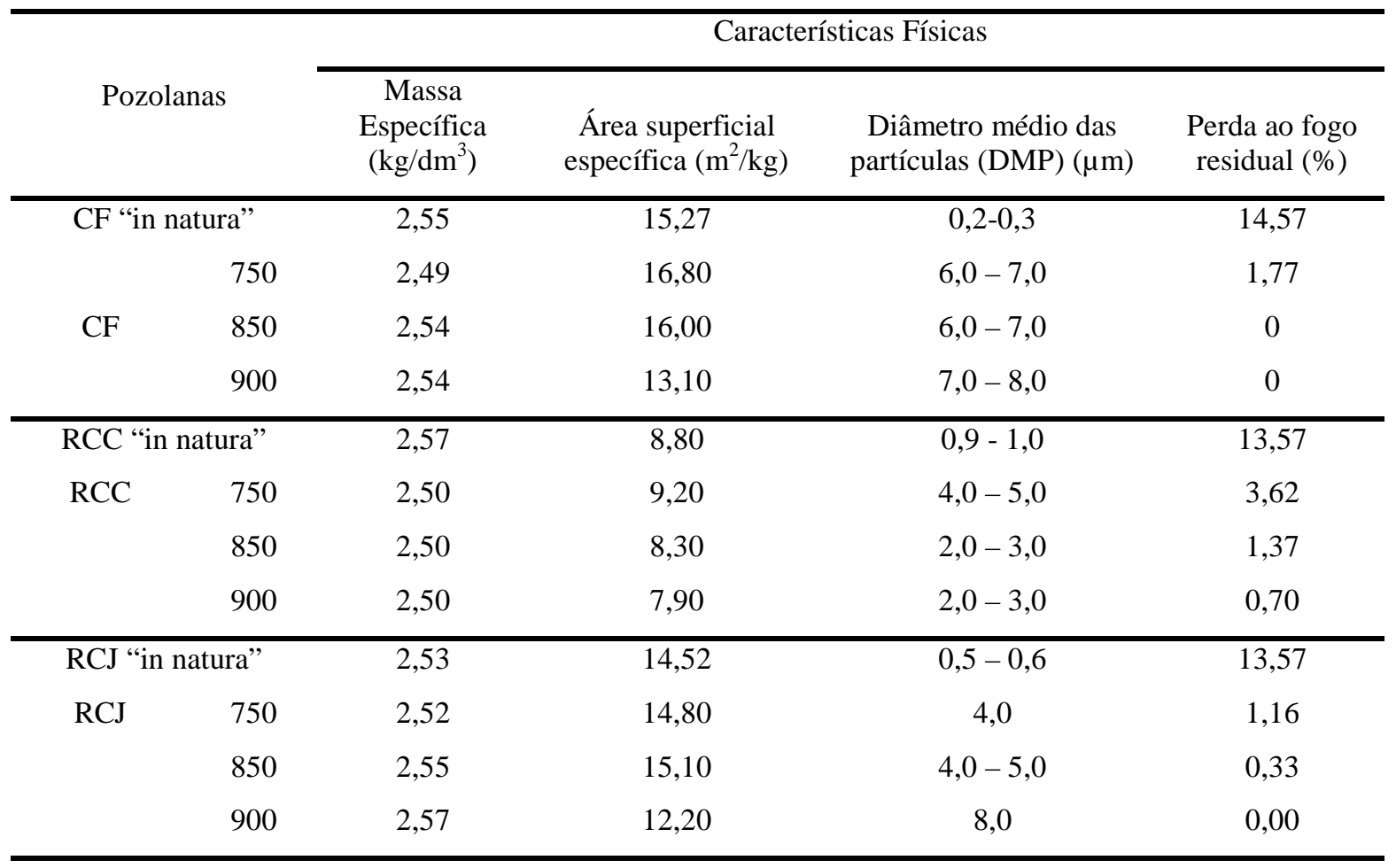

O efeito da temperatura sobre a destruição da estrutura cristalina da caulinita é muito mais pronunciado para aquelas com alto grau de desordem, visto que já possuem naturalmente uma estrutura com maior quantidade de defeitos, que favorece a desidroxilação para quantidades menores de energia. As calcinações do CF e do RCJ proporcionaram, para uma mesma temperatura, pozolanas de caráter amorfo à difração de raios-X mais acentuado do que as produzidas a partir do RCC, que é uma caulinita com menor quantidade de defeitos. 


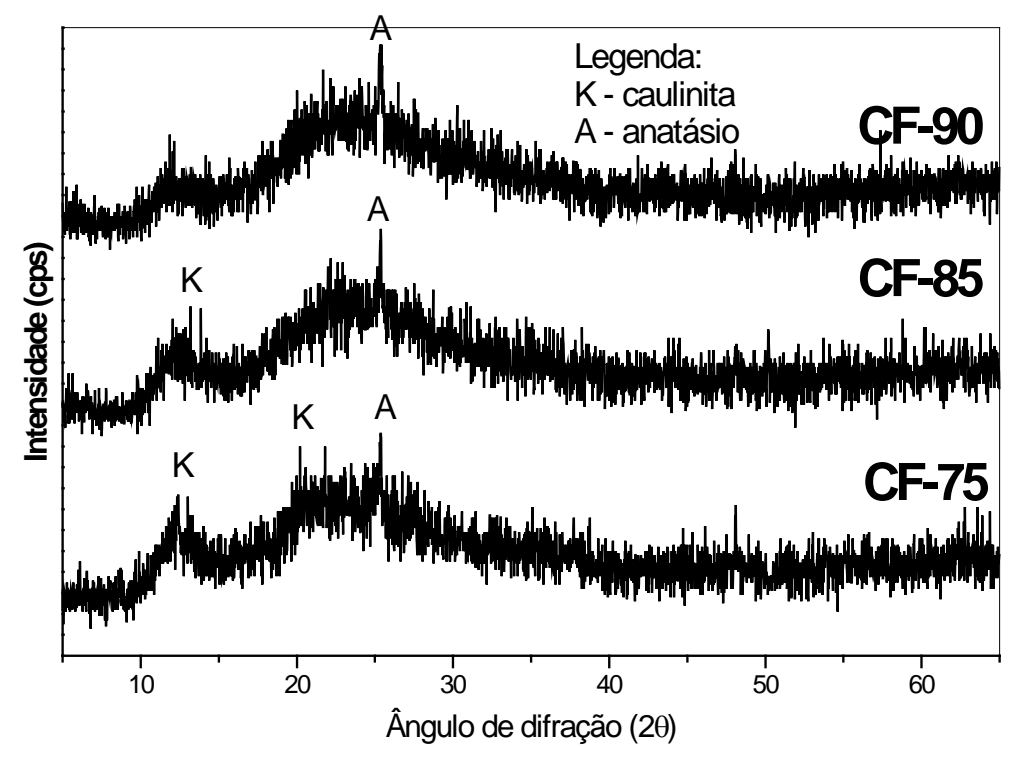

Figura 1: Difratogramas de raios $\mathrm{X}$ dos $\mathrm{CF}$ calcinados a $750^{\circ} \mathrm{C}, 850^{\circ} \mathrm{C}$ e $900^{\circ} \mathrm{C}$.

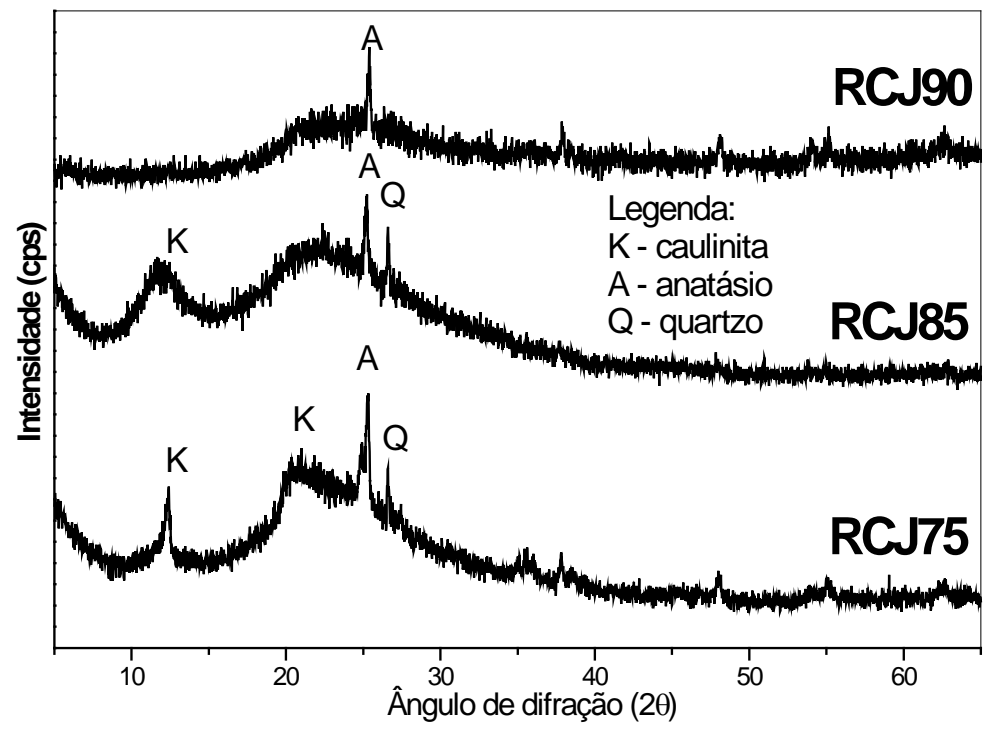

Figura 2: Difratogramas de raios $\mathrm{X}$ dos $\mathrm{RCJ}$ calcinados a $750^{\circ} \mathrm{C}, 850^{\circ} \mathrm{C}$ e $900^{\circ} \mathrm{C}$.

No CF, já não foi possível identificar para a temperatura de $750^{\circ} \mathrm{C}$ os picos de alta intensidade da caulinita, com espaçamentos de 7,15 $\AA$ (principal) e 3,50 $\AA$, localizados próximos a 12,40 e $25,00^{\circ} 2 \theta$, respectivamente. No caso do RCJ, diferentemente do $\mathrm{CF}$, ainda observou-se tanto a $750^{\circ} \mathrm{C}$ quanto a $850^{\circ} \mathrm{C}$ a presença do pico principal da caulinita (Figura 2), embora com a base alargada, denotando um avançado grau de defeitos na sua estrutura cristalina.

O RCJ, apesar de já ter sido caracterizado como uma caulinita de alto grau de defeitos [4], a magnitude desses defeitos é menor quando comparada as da caulinita do CF, aspectos esses evidenciados por BARATA [్] em análises de DRX e IV, nas quais se constatou na caulinita do RCJ a presença de tripletes com reflexões bem definidas entre os ângulos $2 \theta \square$ de $35^{\circ}$ e $40^{\circ}$, o que explica a manutenção de uma quantidade residual de caulinita a $750^{\circ} \mathrm{C}$ e $850^{\circ} \mathrm{C}$, mesmo que parcialmente destruída. 


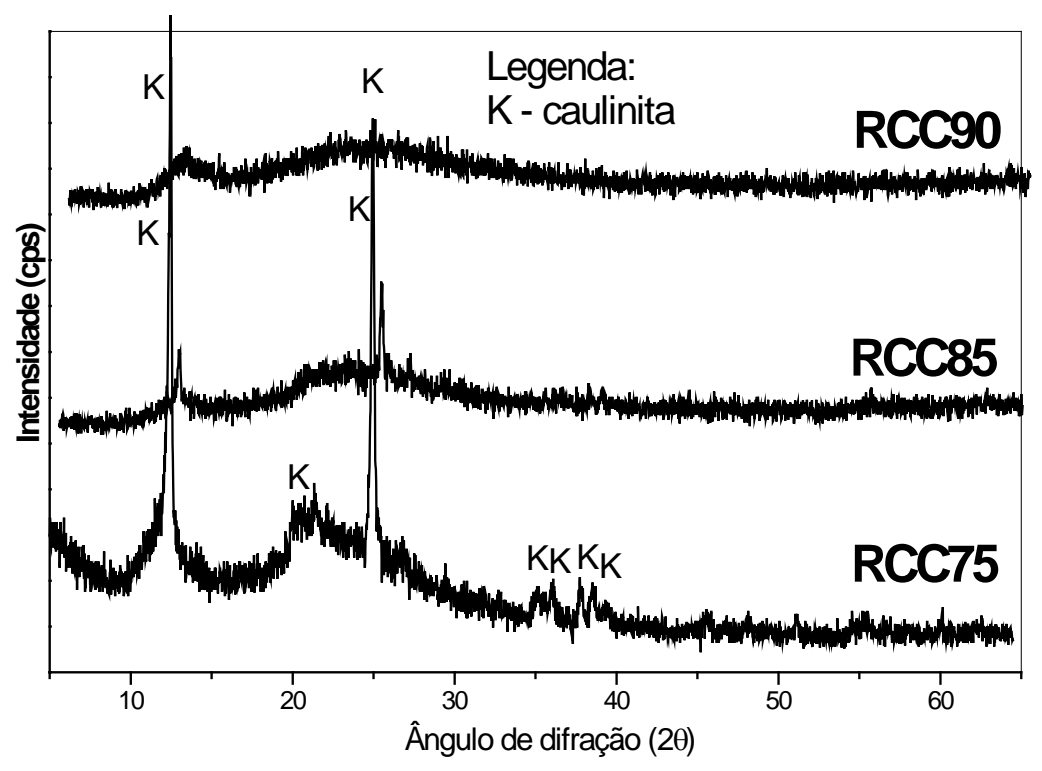

Figura 3: Difratogramas de raios $\mathrm{X}$ do RCC calcinados a $750^{\circ} \mathrm{C}, 850^{\circ} \mathrm{C}$ e $900^{\circ} \mathrm{C}$.

Para o RCC, o desaparecimento completo dos picos de 7,15 e 3,50 Å somente ocorreu à temperatura mais elevada $\left(900^{\circ} \mathrm{C}\right)$. Na pozolana calcinada a $850^{\circ} \mathrm{C}$ ainda havia picos referentes à caulinita residual, bem definidos e agudos, evidenciando o menor grau de desidroxilação do argilomineral, conseqüência do seu arranjo cristalino com baixo grau de defeitos, o que requer maior quantidade de energia para desordenar a estrutura, fato este já constatado por BARATA e ANGELICA [4]. Esse comportamento pode repercutir de modo bastante significativo na decisão de qual matéria-prima explorar no momento de fabricação da pozolana, tendo em vista os maiores custos de produção para alcançar os mesmos patamares de qualidade, ou seja, de reatividade do produto.

Os valores médios de perda ao fogo residual, obtidos na etapa de produção das pozolanas (Tabela 1), também ratificam a tendência observada na DRX. O CF calcinado a $750^{\circ} \mathrm{C}$ já apresentou um percentual de perda ao fogo bastante reduzido, $1,77 \%$, demonstrando que quase toda a caulinita fora convertida em metacaulinita. Para temperaturas superiores essa transformação foi total, indicando a completa desidroxilação desse mineral, o que também foi constatado nas pozolanas produzidas a partir do RCJ. No caso da caulinita com baixo grau de defeitos (RCC), a perda ao fogo residual foi superior para todas as temperaturas estudadas, sendo de $3,62 \%$ a $750^{\circ} \mathrm{C}, 1,37 \%$ a $850^{\circ} \mathrm{C}$ e $0,70 \%$ a $900^{\circ} \mathrm{C}$.

O tratamento térmico provocou, em todas as amostras, independente da temperatura e do tipo de caulim, uma substancial aglomeração das partículas, ocasionando uma alteração na granulometria. Este efeito da aglomeração foi tão expressivo que não foi possível determinar através da difração a laser a distribuição granulométrica das partículas após a calcinação. Em razão disto, essa avaliação somente pode ser realizada após a moagem de todas as amostras calcinadas por 10 minutos em moinho planetário. As Figuras 4 a 6 mostram, para cada tipo de caulim, as variações da distribuição granulométrica em função da temperatura de calcinação.

Esse efeito de aglomeração foi muito mais pronunciado para as caulinitas com maior quantidade de defeitos. No CF houve um aumento no DMP do material “in natura” em relação ao calcinado a $900^{\circ} \mathrm{C}$ de $0,2 \mu \mathrm{m}$ para $8 \mu \mathrm{m}$, respectivamente, o que representa uma majoração de 40 vezes. No RCJ, o DMP passou de 0,5 para $8 \mu \mathrm{m}$, cerca de 16 vezes em comparação com o material "in natura”. Para a caulinita de menor quantidade de defeitos, os aumentos já foram bem menores, cerca de 3 a 6 vezes do tamanho original. $\mathrm{O}$ DMP do RCC passou de 0,9 para $5 \mu \mathrm{m}$ quando calcinado a $750^{\circ} \mathrm{C}$. Cabe salientar que a magnitude do efeito da aglomeração foi muito maior que os números apresentados, pois os mesmos são referentes às granulometrias alteradas pela moagem do material transformado.

Não se observaram acréscimos significativos na granulometria das pozolanas com a elevação da temperatura de queima de $750^{\circ} \mathrm{C}$ para $900^{\circ} \mathrm{C}$. Pelo contrário, para o caso do RCC, o material calcinado a $750^{\circ} \mathrm{C}$ foi o que apresentou o maior DMP. 


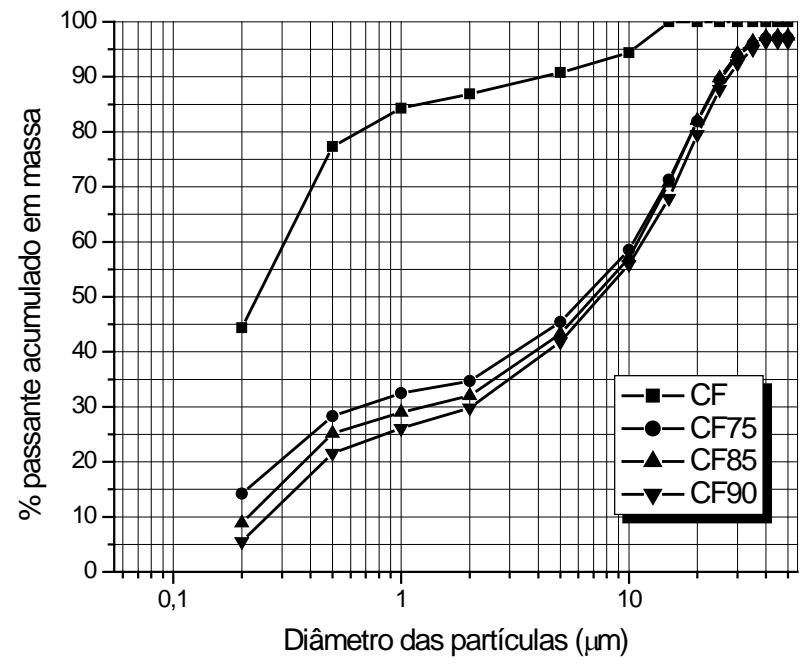

Figura 4: Distribuição granulométrica do CF calcinado a diversas temperaturas e moídos por 10 minutos.

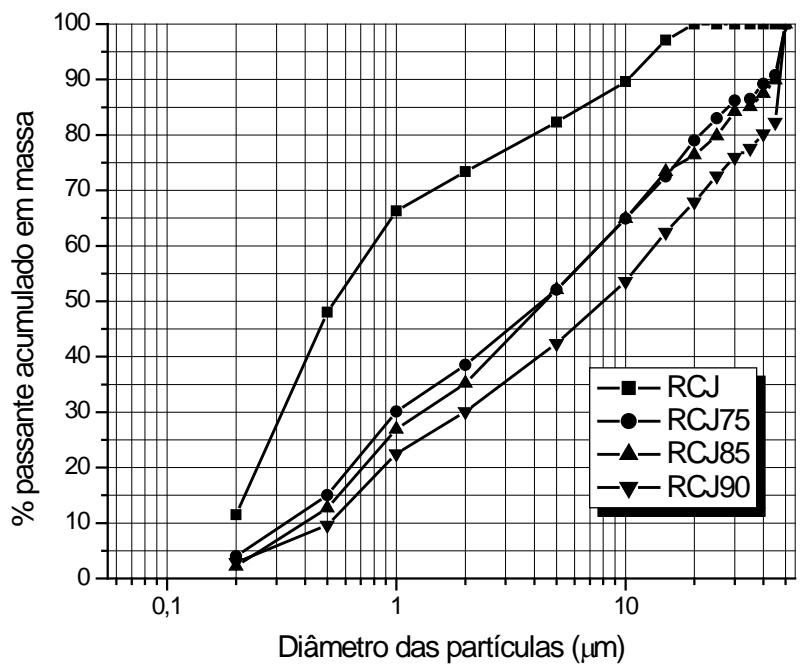

Figura 5: Distribuição granulométrica do RCJ calcinado a diversas temperaturas e moídos por 10 minutos.

As análises granulométricas levam a crer que o a magnitude dos defeitos na estrutura cristalina do argilomineral pode influenciar não somente na reatividade da pozolana, mas também na finura de suas partículas. Segundo MIELENS et al [12], as alterações na área superficial específica e na finura dos argilominerais quando calcinados são atribuídas à desordem parcial da estrutura e a consequente sinterização de suas partículas. Caulinitas com alto grau de defeitos são muito mais suscetíveis à ação da temperatura do que as caulinitas com menor quantidade de defeitos no que concerne ao desordenamento da estrutura cristalina, favorecendo assim a sinterização das partículas de forma mais expressiva. Por essa razão que a magnitude da aglomeração das partículas das pozolanas oriundas do CF e do RCJ foi muito maior em comparação com a das pozolanas do RCC. 


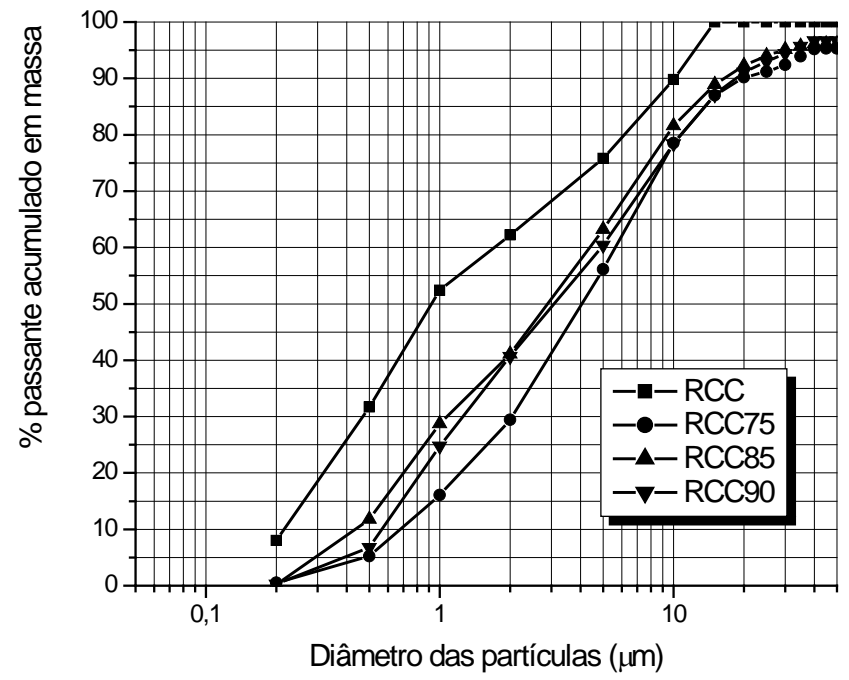

Figura 6: Distribuição granulométrica do RCC calcinado a diversas temperaturas e moídos por 10 minutos.

Esse comportamento colocaria em dúvida a hipótese inicialmente levantada por BARATA e ANGELICA [4] de que as caulinitas com alto grau de defeitos seriam as mais aptas do ponto de vista técnico e, principalmente, econômico para a produção da metacaulinita, haja vista que os seus produtos calcinados necessitariam de um tempo maior de moagem. E isto é o que se busca eliminar ou minimizar, visto que esta etapa representa cerca de 25 a 30\% do custo total de produção da pozolana de argila calcinada. Contudo, para as mesmas condições de moagem, obtiveram-se distribuições granulométricas das partículas similares para todos os resíduos.

Outro aspecto interessante é que apesar da aglomeração das partículas ter sido expressiva, não houve um acompanhamento em iguais proporções nos valores de área superficial específica. As diferenças obtidas entre os materiais de partida e os transformados, independentemente do tipo de caulim, foram ínfimas, mas mostraram uma tendência de redução com o aumento da temperatura de calcinação, possivelmente em razão do início da sinterização e formação de fases precursoras da mullita como o espinélio aluminossilicoso [13]. Entre os diferentes tipos de pozolanas, as oriundas do CF e do RCJ apresentaram áreas superficiais específicas superiores as provenientes do RCC, seguindo a tendência dos materiais de partida.

\subsection{Atividade Pozolânica com Cimento Portland}

Os resultados do ensaio de determinação da atividade pozolânica com cimento Portland de alta resistência inicial (ARI) são apresentados na Tabela 2.

Todas as argamassas com pozolanas apresentaram o mesmo comportamento quanto à demanda de água, exigindo em torno de 19 a 30\% a mais do que a argamassa de referência, percentuais esses que excedem o limite máximo estipulado pela norma [10] de 15\%. Essa quantidade elevada de água para alcançar a consistência prescrita no método de ensaio é consequência da extrema finura dessas pozolanas, cujos diâmetros variam entre 2 e $8 \mu \mathrm{m}$ e as áreas superficiais específicas entre 8 e $17 \mathrm{~m}^{2} / \mathrm{g}$. Por essa razão, o uso desses caulins calcinados em sistemas a base de cimento Portland (pastas, grautes, argamassas e concretos) geralmente estará associado ao empregado de aditivos redutores de água. Esse comportamento ratifica os resultados obtidos em outros trabalhos científicos, que relatam que a incorporação do MCAR aos sistemas de cimento Portland (concretos, argamassas, pastas) requer uma quantidade de água superior a das misturas de referência ou uma dosagem maior de aditivos $[\underline{5}, \underline{14}, \underline{15}]$.

Ainda sobre o requerimento excessivo de água, outro aspecto a ser ressaltado é que a norma em questão está formulada para pozolanas de média a baixa reatividade, que geralmente são incorporadas em percentuais relativamente elevados devido o diâmetro das partículas serem maiores. A norma brasileira [10] prescreve que o volume de substituição do cimento pela pozolana é de $35 \%$, o que corresponde a $30 \%$ em massa para os caulins calcinados, valores excessivamente altos para pozolanas de alta reatividade, cujo teor ideal de incorporação seria de até $10 \%$ sobre a massa de cimento. MALHOTRA e MEHTA [16] citam o 
exemplo da norma Canadense, CSA-A 23.5, que prescreve a incorporação de apenas 10\% de SA sobre a massa de cimento nas argamassas.

Tabela 2: Índice de Atividade Pozolânica com cimento Portland ARI.

\begin{tabular}{|c|c|c|c|c|c|c|}
\hline Argamassa & $\begin{array}{l}\text { Demanda de } \\
\text { água }(\%)\end{array}$ & $\begin{array}{c}\text { Consistência } \\
\text { Padrão } \\
(225 \pm 5 \mathrm{~mm}) \\
\end{array}$ & $\begin{array}{c}\text { Relação } \\
\text { água/aglomerante }\end{array}$ & $\begin{array}{c}\text { I.A.P. } \\
(\%)\end{array}$ & $\begin{array}{c}\mathbf{f}_{\text {cmédio }}{ }^{(1)} \\
\text { (MPa) }\end{array}$ & $\begin{array}{c}\text { Desvio } \\
\text { Padrão } \\
\text { (MPa) }\end{array}$ \\
\hline Referência & 100 & 225,80 & 0,59 & - & 45,50 & \multirow{12}{*}{2,25} \\
\hline CF75 & 124 & 223,10 & 0,78 & 95,40 & 43,40 & \\
\hline CF85 & 127 & 226,70 & 0,80 & 92,20 & 41,90 & \\
\hline CF90 & 130 & 229,25 & 0,81 & 93,00 & 40,30 & \\
\hline RCC75 & 122 & 225,90 & 0,77 & 84,60 & 38,50 & \\
\hline RCC85 & 119 & 222,60 & 0,75 & 90,40 & 41,10 & \\
\hline RCC90 & 119 & 225,30 & 0,75 & 95,20 & 43,30 & \\
\hline RCJ75 & 125 & 225,10 & 0,76 & 92,10 & 41,90 & \\
\hline RCJ85 & 123 & 222,60 & 0,77 & 94,90 & 43,10 & \\
\hline RCJ90 & 121 & 229,50 & 0,75 & 90,80 & 41,30 & \\
\hline SA & 132 & 220,10 & 0,87 & 86,51 & 39,30 & \\
\hline MI & 120 & 224,15 & 0,75 & 88,30 & 40,10 & \\
\hline
\end{tabular}

Observação:

${ }^{(1)}$ Valor médio de resistência à compressão

Neste trabalho, o ensaio realizado demonstra que todas as pozolanas, independente do material de partida empregado e da faixa de temperatura estudada, possuem uma reatividade extremamente elevada, com índices entre 85 e 95\%, muito acima do mínimo de 75\% estipulado pela norma [17] e superiores aos obtidos com as pozolanas de alta reatividade como a SA e o MI.

Não houve diferenças de reatividade entre as pozolanas produzidas a partir das caulinitas com maior e menor quantidade de defeitos. Os caulins calcinados provenientes do CF, do RCJ e do RCC atingiram IAP entre 94 e 95\%. Contudo, esses máximos foram alcançados em temperaturas distintas para cada tipo de caulim em virtude da quantidade de defeitos no retículo cristalino influenciar decisivamente sobre a temperatura mais adequada para a produção da pozolana. As pozolanas obtidas a partir das caulinitas com alto grau de defeitos apresentaram reatividades mais elevadas a temperaturas mais baixas do que as pozolanas provenientes da caulinita com menor quantidade de defeitos. O CF alcançou a maior atividade pozolânica quando calcinado a $750^{\circ} \mathrm{C}$, enquanto que o RCJ foi a $850^{\circ} \mathrm{C}$ e o RCC a $900^{\circ} \mathrm{C}$.

Esses resultados ratificam a hipótese levantada por BARATA e ANGELICA [4] de que as caulinitas com maior quantidade de defeitos produzem metacaulinitas de maior reatividade em razão da maior taxa de desidroxilação. No caso em questão, a caulinita com menor quantidade de defeitos, RCC, produziu pozolanas de menor reatividade para temperaturas de calcinação mais baixas. Todavia, quando calcinada a temperatura mais elevada, a reatividade alcançou o mesmo patamar das pozolanas oriundas das caulinita com maior quantidade de defeitos.

O aumento na temperatura de calcinação não ocasionou nas pozolanas produzidas a partir caulinitas com alto grau de defeitos (CF e RCJ), diferenças significativas na atividade pozolânica. Não se configurou uma correlação direta entre a atividade pozolânica e a temperatura, ao passo que na caulinita com baixo grau de defeitos, quanto maior a temperatura de calcinação maior foi a reatividade alcançada. Como o CF e o RCJ naturalmente já possuem grande quantidade de defeitos na estrutura cristalina, a ativação térmica a $750^{\circ} \mathrm{C}$ já foi o suficiente para ocasionar uma desordem de magnitude mais acentuada do que aquela acarretada ao RCC. Este por sua vez demandou temperaturas mais elevadas para destruir completamente a estrutura da sua caulinita, com menor quantidade de defeitos. Exemplificando, o IAP do RCC90 foi 13\% e 5\% superior ao do RCC75 e RCC85, respectivamente. Estes acréscimos são bastante expressivos, proporcionando ganhos expressivos na reatividade, e por isso justificam a produção da pozolana a temperaturas mais elevadas.

Para validar estatisticamente essas considerações e auxiliar na decisão da temperatura ótima de calcinação, foram efetuadas 03 análises de variância (ANOVA) para o nível de 5\% de significância, uma para cada tipo de resíduo, com os dados obtidos no experimento, excluindo os referentes às SA e MI. Os resultados das análises de variância, apresentados nas Tabelas 03 a 05, comprovaram as considerações expostas anteriormente, demonstrando que a temperatura de calcinação foi significativa para a reatividade somente para a caulinita com menor grau de defeitos (RCC). Para investigar qual a temperatura que proporciona diferenças significativas nesse grupo de pozolanas, realizou-se a comparação múltipla de médias (CMM) (Tabela 6), que comprovou que a reatividade da RCC90 foi significativamente superior a das demais pozolanas, calcinadas em temperaturas inferiores. Quanto as caulinitas RCJ e CF, a ANOVA não acusou 
diferenças significativas entre os materiais calcinados entre $750^{\circ} \mathrm{C}, 850^{\circ} \mathrm{C}$ e $900^{\circ} \mathrm{C}$, embora numericamente algum valor seja superior a outro, contudo, essa variação é inerente ao próprio ensaio e à amostragem dos materiais.

Em suma, é preferível adotar temperaturas mais reduzidas para a produção de pozolanas a partir das caulinitas com maiores defeitos na estrutura cristalina, tendo em vista que não ocorrerão incrementos na reatividade quando do aumento da temperatura. No caso do RCC, a situação é distinta, temperaturas mais elevadas são necessárias para a obtenção de pozolanas com reatividades satisfatórias.

Tabela 3: Análise de variância das reatividades das pozolanas CF.

\begin{tabular}{c|c|c|c|c|c|c}
\hline Fator & SQ & GDL & MQ & Fcalc. & F0,05 & Significânica \\
\hline Temperatura & 13,81 & 2 & 6,90 & 2,83 & 4,46 & DNS1 \\
\hline Erro & 14,63 & 6 & 2,44 & & & \\
\hline TOTAL & 28,44 & 8 & & & & \\
\hline
\end{tabular}

Observações:

${ }^{1}$ Diferença não significativa $\left(\mathrm{F}_{\text {calc. }}<\mathrm{F}_{0,05}\right)$

Tabela 4: Análise de variância das reatividades das pozolanas RCJ.

\begin{tabular}{c|c|c|c|c|c|c}
\hline Fator & SQ & GDL & MQ & Fcalc. & F0,05 & Significânica \\
\hline Temperatura & 5,29 & 2 & 2,64 & 1,63 & 4,46 & DNS1 \\
\hline Erro & 9,73 & 6 & 1,62 & & & \\
\hline TOTAL & 15,02 & 8 & & & & \\
\hline
\end{tabular}

Observações:

${ }^{1}$ Diferença não significativa $\left(\mathrm{F}_{\text {calc. }}<\mathrm{F}_{0,05}\right)$

Tabela 5: Análise de variância das reatividades das pozolanas RCC.

\begin{tabular}{c|c|c|c|c|c|c}
\hline Fator & SQ & GDL & MQ & Fcalc. & F0,05 & Significânica \\
\hline Temperatura & 34,67 & 2 & 17,33 & 16,17 & 4,46 & DS1 \\
\hline Erro & 6,43 & 6 & 1,07 & & & \\
\hline TOTAL & 41,10 & 8 & & & & \\
\hline
\end{tabular}

Observações:

${ }^{1}$ Diferença significativa $\left(\mathrm{F}_{\text {calc. }}>\mathrm{F}_{0,05}\right)$

Tabela 6: Comparação múltipla de médias das reatividades das pozolanas RCC.

\begin{tabular}{c|c|c|c}
\hline Diferença de IAP & Valor obtido (MPa) & Limite de Decisão (Ld) & Significância \\
\hline RCC90 - RCC75 & 4,80 & \multirow{2}{*}{1,79} & DS \\
\hline RCC90 - RCC85 & 2,17 & & DS \\
\hline RCC85 - RCC75 & 2,63 & & DS \\
\hline
\end{tabular}

Observações:

Diferença significativa (Valor obtido > Ld)

\subsection{Atividade Pozolânica: Ensaio "Chapelle" Modificado}

Os resultados do ensaio de “Chapelle” modificado são mostrados na Tabela 7. Os valores médios obtidos para todas as pozolanas foram extremamente elevados, compreendidos entre 738 e $852 \mathrm{mg} \mathrm{CaO} / \mathrm{g}$ pozolana, superiores aos obtidos com SA e o MI, pozolanas de alta reatividade disponíveis comercialmente, o que demonstra a alta reatividade da metacaulinita produzida com estes tipos de caulins.

Apesar do ensaio de "Chapelle" ser um teste acelerado, executado a alta temperatura, cujos resultados não fornecem qualquer informação sobre a taxa da reação pozolânica a temperatura ambiente, demonstrou excelente correlação com o ensaio mecânico. Com as pozolanas CF, não ocorreram acréscimos de reatividade com o aumento da temperatura de calcinação de $750^{\circ}$ para $900^{\circ} \mathrm{C}$ em razão da elevada quantidade de defeitos que essa caulinita já apresenta naturalmente. Para as pozolanas RCC e RCJ, a temperatura foi o fator significativo para o aumento da reatividade. 
Tabela 7: Resultados do ensaio de "Chapelle”.

\begin{tabular}{|c|c|c|}
\hline Pozolanas & $\begin{array}{c}\text { Reatividade “Chapelle” } \\
\text { média } \\
\text { (mg CaO / g pozolana) }\end{array}$ & $\begin{array}{c}\text { Desvio Padrão } \\
\text { (mg CaO / g pozolana) }\end{array}$ \\
\hline CF75 & 791 & \multirow{11}{*}{24,80} \\
\hline CF85 & 804 & \\
\hline CF90 & 806 & \\
\hline RCC75 & 738 & \\
\hline RCC85 & 827 & \\
\hline RCC90 & 847 & \\
\hline RCJ75 & 765 & \\
\hline RCJ85 & 845 & \\
\hline RCJ90 & 852 & \\
\hline SA & 773 & \\
\hline MI & 764 & \\
\hline
\end{tabular}

\subsection{Temperatura Ótima de Calcinação}

No CF, por ser uma caulinita com alto grau de defeitos, as diferenças foram diminutas entre as reatividades das pozolanas quando se aumentou a temperatura de calcinação, conforme mostrado na Figura 7, na qual são comparados os resultados dos métodos de ensaios adotados. A tendência em ambos os ensaios é a reatividade permanecer praticamente constante para todas as temperaturas estudadas, fato este comprovado estatisticamente pela ANOVA, o que faz com que a escolha recaia sobre a menor, $750^{\circ} \mathrm{C}$.

No caso das pozolanas provenientes do RCC, para que as mesmas apresentassem atividade pozolânica satisfatória foi necessário produzi-las a temperaturas elevadas, $900^{\circ} \mathrm{C}$. Na Figura 8, observa-se claramente a tendência de crescimento da atividade pozolânica com o incremento da temperatura para ambos os ensaios. Resultados também comprovados estatísticamente pela ANOVA e pela CCM.

A respeito do RCJ, por se tratar de caulinita com características intermediárias de cristalinidade, dentre as estudadas, suas pozolanas também demonstraram o mesmo comportamento. Como se trata de uma caulinita com alta quantidade de defeitos, todavia, inferior a do CF, a produção de pozolanas com reatividade satisfatória demandou uma quantidade de energia maior que a do CF, mas inferior a do RCC. Este comportamento pode ser detectado claramente no ensaio "Chapelle”, no qual houve um aumento nítido da reatividade até $850^{\circ} \mathrm{C}$, a partir daí o acréscimo foi desprezível (Figura 9). No ensaio com cimento Portland este comportamento não ficou evidenciado. Como a análise estatística se baseou nos dados deste ensaio, a ANOVA não apontou diferenças significativas entre as temperaturas de calcinação estudadas. Neste caso, a temperatura mais adequada para a produção do RCJ estaria compreendida entre $750^{\circ}$ e $850^{\circ} \mathrm{C}$.

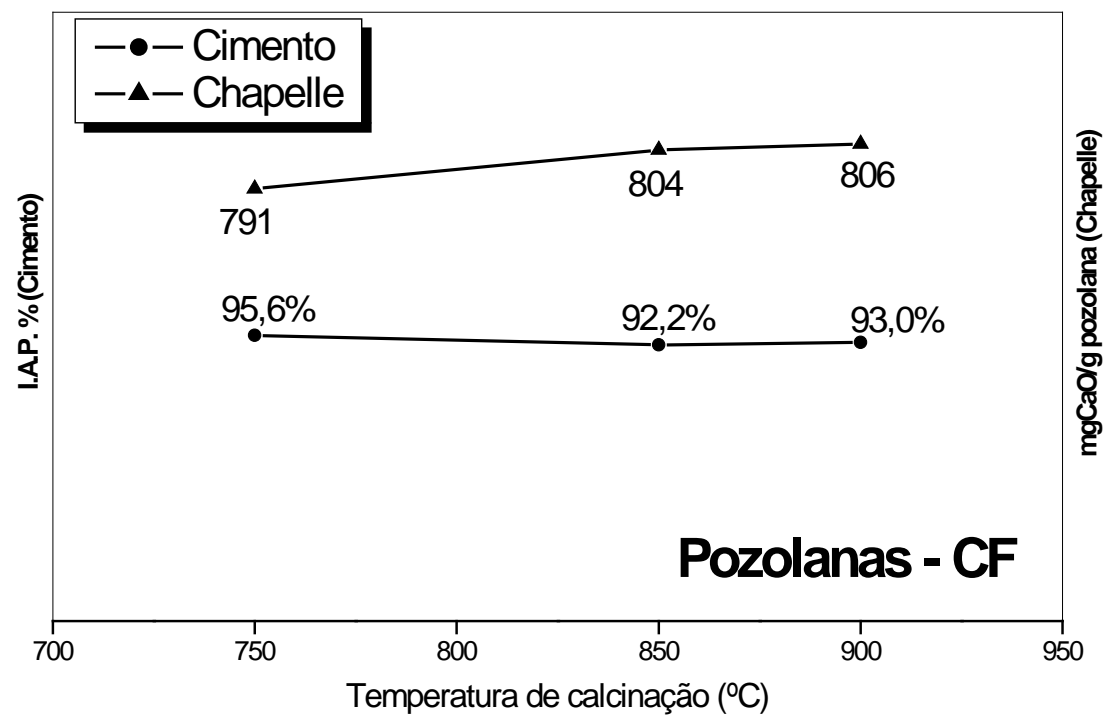

Figura 7: Comparação da atividade pozolânica do CF75, CF85, CF90 através de diversos métodos. 


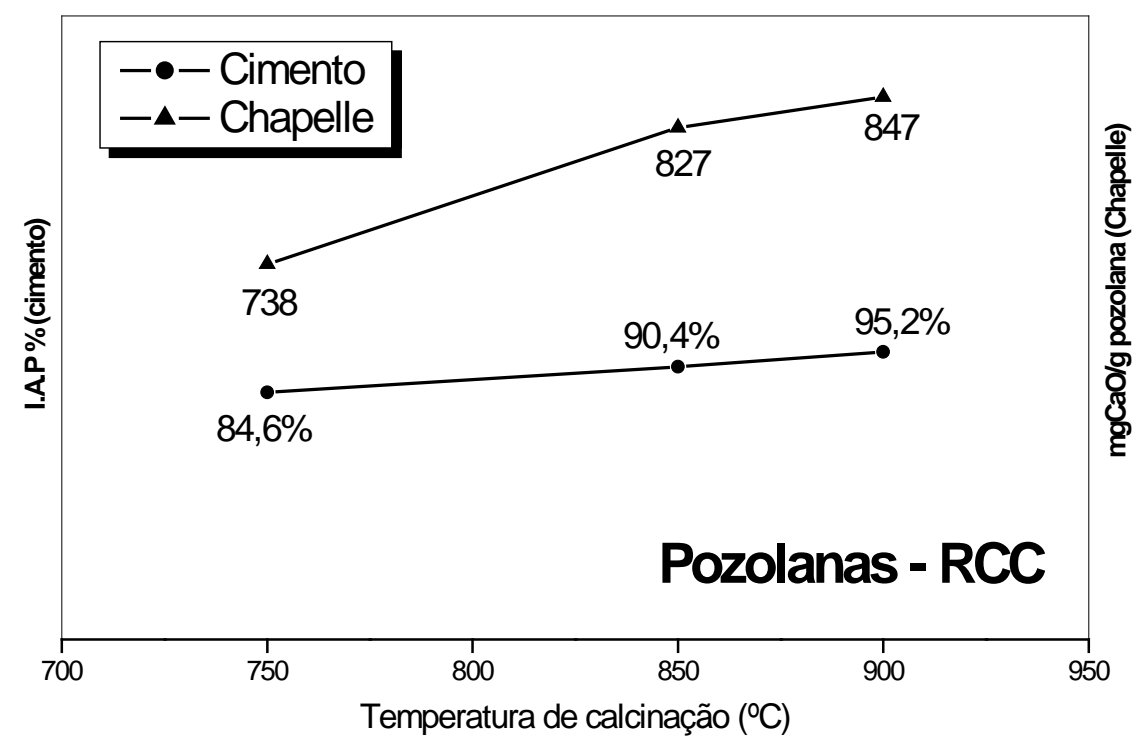

Figura 8: Comparação da atividade pozolânica do RCC75, RCC85, RCC90 através de diversos métodos.

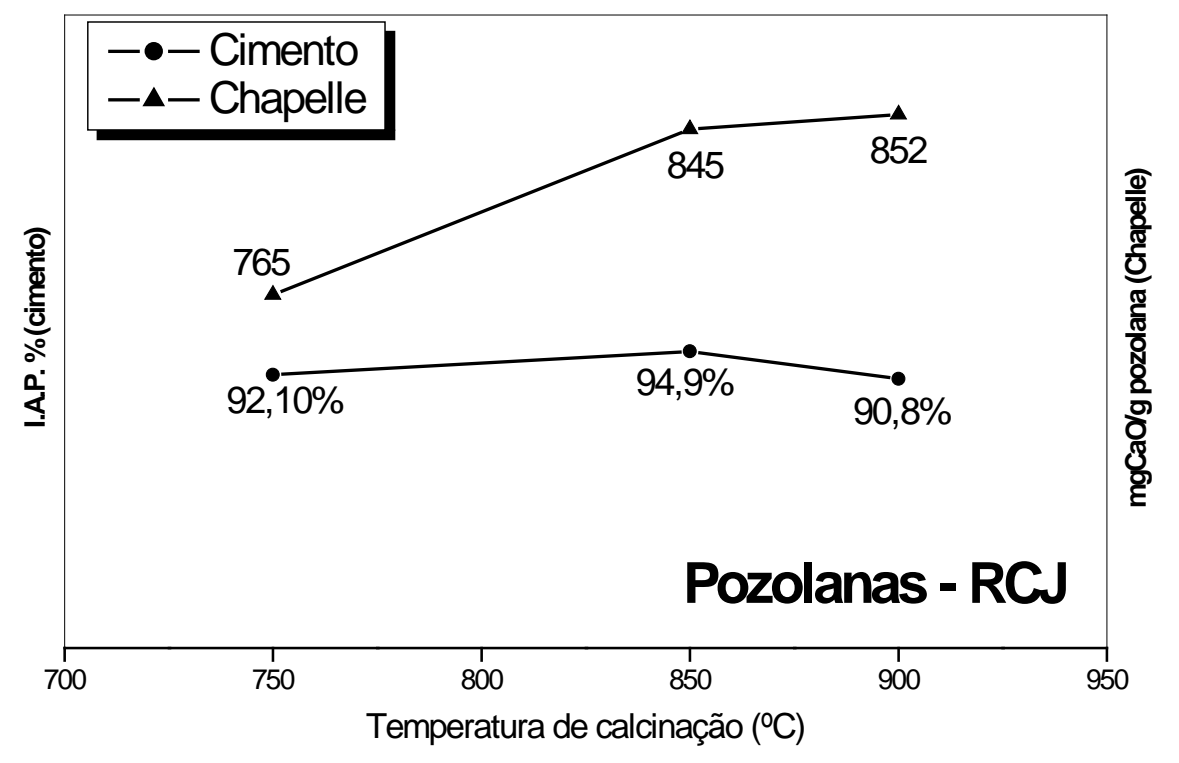

Figura 9: Comparação da atividade pozolânica do RCJ75, RCJ85, RCJ90 através de diversos métodos.

A diferença muito acentuada de reatividade entre o MCAR proveniente dos resíduos e as pozolanas comerciais deve ser analisada com prudência, pois a variabilidade inerente aos processos em escala industrial pode ter proporcionados produtos com baixa qualidade, ao passo que os resíduos foram processados em condições ótimas de laboratório.

Em comparação ao MI, é possível que os resíduos possam proporcionar um custo menor de produção em relação às demais matérias-primas provenientes de depósitos primários, tendo em vista que não há a necessidade de uma etapa de beneficiamento da matéria-prima e as temperaturas de queima são menores, caso sejam utilizadas as caulinitas com maior quantidade de defeitos. Com relação à SA, as vantagens do MCAR são, além da reatividade, uma maior uniformidade das suas características. 
Em suma, pode-se afirmar que as temperaturas ótimas de calcinação para o CF, RCJ e RCC foram respectivamente $750^{\circ} \mathrm{C}, 850^{\circ} \mathrm{C}$ e $900^{\circ} \mathrm{C}$, obedecendo a uma escala gradativa relacionada à quantidade de defeitos das caulinitas. Esses resultados apresentaram boa correlação com os demais trabalhos, nos quais a temperatura ótima de calcinação encontra-se entre $650^{\circ} \mathrm{C}$ e $850^{\circ} \mathrm{C}[\underline{18}, \underline{19}$, 20]. Esse intervalo é semelhante ao recomendado pela norma indiana IS 1344 , entre $700^{\circ} \mathrm{C}$ e $800^{\circ} \mathrm{C}$ []. A divergência ficou por conta do RCC, que necessitou de $900^{\circ} \mathrm{C}$ para proporcionar atividade pozolânica satisfatória devido a sua menor quantidade de defeitos.

\section{CONCLUSÕES}

- O efeito da temperatura sobre a destruição da estrutura cristalina da caulinita foi muito mais pronunciado para aquelas com maior quantidade de defeitos, o que favorece a desidroxilação com o emprego de quantidades menores de energia.

- O emprego de caulinitas com maior quantidade de defeitos na estrutura cristalina reduz as temperaturas de produção das pozolanas, sem que haja perda de qualidade ou de reatividade do produto;

- $\quad$ Nos ensaios de atividade pozolânica, sejam esses mecânico ou químico, observou-se que todas as pozolanas, independentemente do material de partida empregado e da faixa de temperatura estudada, possuem uma reatividade elevada. No método com cimento Portland, os índices de atividade pozolânica ficaram entre $85 \%$ e $95 \%$. No ensaio de "Chapelle" modificado, a reatividade ficou compreendida entre 738 e $852 \mathrm{mg} \mathrm{CaO} / \mathrm{g}$ pozolana;

- Os resultados de reatividade obtidos com os resíduos cauliníticos, processados e não processados, foram superiores aos obtidos com as pozolanas disponíveis comercialmente, como a SA e o MI.;

- O tratamento térmico provocou uma substancial aglomeração das partículas dos resíduos. As caulinitas com alto grau de defeitos foram muito mais suscetíveis à aglomeração das partículas pela ação da temperatura do que as caulinitas com menor quantidade de defeitos no que concerne ao desordenamento da estrutura cristalina;

\section{AGRADECIMENTOS}

A empresa Vale pelo financiamento que tornou possível a realização deste trabalho.

\section{BIBLIOGRAFIA}

[1] Departamento Nacional de Produção Mineral, http://www.dnpm.gov.br/assets/galeriaDocumento/AMB2006/I_2006.pdf, Acessado em outubro de 2007.

[2] DUARTE, A.L., Caulim do Morro do Felipe, Baixo Rio Jari, contexto geológico e gênese, Dissertação de M.Sc., CPGG/IG/UFPA, Belém, PA, Brasil, 1996.

[3] SOUSA, D.J.L., Caracterização geológica, mineralógica, química e física do caulim da mina da RCC Rio Capim (PA), Dissertação de M.Sc., CPGG/IG/UFPA, Belém, PA, Brasil, 2000.

[4] BARATA, M.S., ANGELICA, R.S., "Caracterização dos resíduos cauliníticos das indústrias de mineração de caulim da Amazônia como material-prima para produção de pozolanas de alta reatividade”, Cerâmica, v. 58, n. 345, pp. 36-42, 2012.

[5] BARATA, M.S., Aproveitamento dos resíduos cauliníticos das industrias de beneficiamento de caulim da região Amazônica como matéria-prima para fabricação de um material de construção (pozolanas), Tese de D.Sc., CPGG/IG/UFPA, Belém, PA, Brasil, 2007.

[6] MURAT, M., "Hydratation reaction and hardening of calcined clays and related minerals. I - Preliminary investigation on metakaolinite”, Cement and Concrete Research, v. 13, pp. 259-266, 1983. 
[7] AMBROISE, J., MURAT, M., PERA, J., "Hydratation reaction and hardening of calcined clays and related minerals. IV - Experimental conditions for strength improvement on metakaolinite minicylinder”, Cement and Concrete Research, v. 15, pp. 83-88, 1985.

[8] WILD, S., KHATIB, J.M., JONES, A., "Relative strength, pozzolanic activity and cement hydration in superplasticised metakaolin concrete”, Cement and Concrete Research, v. 26, n. 10, pp. 1537-1544, 1996.

[9] AMBROISE, J., MARTIN-CALLE, S., PERA, J., "Pozzolanic behavior of thermally activated kaolin”, In: International Conference on Fly Ash, Silica Fume, Slag and Natural Pozolans in Concrete, 73148, Istanbul, TURKEY, 1993.

[10] ASSOCIAÇÃO BRASILEIRA DE NORMAS TÉCNICAS, NBR 5752: Materiais pozolânicos Determinação da atividade pozolânica com Cimento Portland - Índice de Atividade Pozolânica com Cimento: Método de ensaio. Rio de Janeiro, 1992.

[11] ASSOCIAÇÃO BRASILEIRA DE NORMAS TÉCNICAS, NBR 5733: Cimento Portland de alta resistência inicial: Especificação. Rio de Janeiro, 1991.

[12] MIELENS, R.C., WITTE, L.P., GLANTZ, O.J., "Effect of calcination on natrual pozzolans. In: AMERICAN SOCIETY FOR TESTING MATERIALS (ASTM). Symposium on use of pozzolanic materials in mortas and concrete. 43-92, Philadelphia, USA, 1950.

[13] SOUZA SANTOS, P., Ciência e tecnologia de argila. 2 ed., São Paulo, Edgard Blücher, 1992.

[14] CALDARONE, M.A., GRUBER, K.A., BURG, R.G., "High-reactivity metakaolin: a new generation mineral admixture”, Concrete International, v. 16, n. 11, pp. 37-40, 1994.

[15] ZHANG, M.H., MALHOTRA, V.M., "Characteristics of a thermally activated alumino-silicate pozzolanic material and its use in concrete”, Cement and Concrete Research, v. 25, n. 8, p. 17131725, 1995.

[16] MALhOtRA, V.M., MEHTA, P.K., Pozzolanic and cementitious materials, Ottawa, Advanced Concrete Technology Program/CANMET, 1996.

[17] ASSOCIAÇÃO BRASILEIRA DE NORMAS TÉCNICAS, NBR 12653: Materiais pozolânicos: Especificação. Rio de Janeiro, 1992.

[18] MIELENS, R.C., WITTE, L.P., GLANTZ, O.J., "Effect of calcination on natural pozzolans". In: AMERICAN SOCIETY FOR TESTING MATERIALS (ASTM). Symposium on use of pozzolanic materials in mortas and concrete, 43-92, Philadelphia, USA, 1950.

[19] RUAS, A.P. L., Produção de pozolana artificial. In: Reunião de Técnicos da indústria do cimento, ABCP, São Paulo, 1972.

[20] SAAD, M., ANDRADE, W.P., PAULON, V.A., "Properties of mass concrete containing an active pozzolan made from clay”, Concrete International, v. 4, n. 7, p. 59-65, 1982. 